\title{
COMPORTAMENTO DO MAMOEIRO SEKATI NAS CONDIÇÕES DO OESTE DA BAHIA $^{1}$
}

\author{
OSVALDO KIYOSHI YAMANISHI², RODRIGO MARQUES DE MELLO ${ }^{3}$, VLADSON ARAÚJO MARTINS ${ }^{3}$, \\ LUCIMAR ANDRADE DE LIMA3, GENI RODRIGUES FAGUNDES ${ }^{4}$
}

\begin{abstract}
RESUMO - Avaliaram-se as características fenotípicas das plantas e físicas e químicas dos frutos da variedade Sekati e do híbrido Tainung 01 produzidos no oeste da Bahia na primavera e no verão. Nas plantas analisadas na primavera, houve diferença significativa entre a variedade Sekati e o híbrido Tainung 01 para as características: altura de planta, diâmetro do caule, $\mathrm{n}^{\circ}$ de frutos, teor de clorofila e incidência de mancha fisiológica nos frutos, sendo obtidos maiores valores no híbrido Tainung 01. No verão, o comprimento da nervura central e o teor de clorofila não variaram entre as cultivares. A variedade Sekati não apresentou sintomas de mancha fisiológica nos frutos, nas épocas estudadas. Os frutos de 'Sekati' colhidos na primavera apresentaram maiores médias de peso $(1.525 \mathrm{~g})$, firmeza $\left(3,10 \mathrm{~kg} / \mathrm{cm}^{2}\right)$ e espessura de polpa $(31,8 \mathrm{~cm}), \mathrm{pH}(5,65)$ e AT $(0,124 \%$ ácido cítrico). A vida útil pós-colheita dos frutos das duas cultivares colhidos na primavera e mantidos sob temperatura ambiente foi menor que a dos frutos colhidos no verão; já nos frutos mantidos sob refrigeração, a vida útil foi maior na primavera. A variedade Sekati, apesar de ter apresentado menor quantidade de frutos, destacou-se por apresentar menor altura de planta, maior tolerância à mancha fisiológica dos frutos e valores médios próximos aos do híbrido Tainung 01 para a maioria das características físicas e químicas analisadas.
\end{abstract}

Termos para indexação: Carica papaya, características fenotípicas, qualidade, pós-colheita.

\section{BEHAVIOR OF SEKATI PAPAYA UNDER CONDITIONS OF THE WESTERN BAHIA}

\begin{abstract}
The phenotypic characteristics of the plants and physical and chemical characteristics of fruits of Sekati variety and Tainung 01 hybrid grown under condition of the western Bahia during spring and summer, were evaluated. In the spring, Tainung 01 plants showed significant higher values compared to Sekati in the following characteristics: plant height, stem diameter, fruit number, chlorophyll content and incidence of skin freckles. In the summer, the length of leaf central vein and chlorophyll content did not differ among the genotypes. Sekati did not show skin freckles in the fruits during the evaluated period. Sekati fruit harvested during spring had higher average values for weight $(1525 \mathrm{~g})$, firmness $\left(3.10 \mathrm{~kg} / \mathrm{cm}^{2}\right)$ and pulp thickness $(31.8 \mathrm{~cm}), \mathrm{pH}(5.6)$ and TA (0.124\% citric acid). Fruit shelf life of both genotype harvested during spring and stored under ambient temperature were shorter than fruits harvested during summer, on the other hand, fruits stored under refrigeration the shelf life was longer for those fruits harvested during spring. Sekati variety in spite of having lesser amount of fruits displayed dwarfness, tolerance to skin freckles and physical and chemical characteristics of fruits similar to Tainung 01 .
\end{abstract}

Index terms: Carica papaya, phenotypic characteristics, quality, post-harvest.

\section{INTRODUÇÃO}

O consumo mundial de mamão tem apresentado crescimento surpreendente nos últimos anos, deflagrando no aumento das exportações dos países produtores. Felizmente, o Brasil vem acompanhando esta tendência, fato este, facilmente notado ao se observar a importância que o mamão e as demais frutas tropicais vêm apresentando sobre o Produto Interno Bruto do País (Lima, 2003).

No ano de 2001, a produção mundial de mamão atingiu 5,4 milhões de toneladas, quando o Brasil foi o maior produtor mundial (1.439.712 toneladas). A quantidade exportada cresceu $289,8 \%$ entre 1997 e 2001, mas, mesmo assim, o Brasil ficou como o segundo maior exportador da fruta (Agrianual, 2003).

Dentre as cultivares mais comercializadas estão: Sunrise Solo e Golden, do grupo 'Solo', e o híbrido Tainung 01, do grupo 'Formosa' (Costa e Pacova, 2003). Mas, segundo Dantas e Morales (1996), o elevado preço e a dificuldade de obtenção de sementes importadas do híbrido do grupo 'Formosa' constituem fatores limitantes à expansão desta cultura. Outro fator a ser considerado é a suscetibilidade destas cultivares à mancha fisiológica (Marin et al., 2002).

A qualidade do mamão tem sido seriamente comprometida pela mancha fisiológica, que causa lesões celulares que afetam a aparência externa da casca e a estética da fruta, não provocando alteração no sabor, aroma e no valor nutritivo, porém causam enorme desvalorização do fruto na comercialização (Ventura et al., 2003; Lima, 2003). De acordo com Ueno et al. (2002), a qualidade dos frutos de mamoeiro produzidos no oeste da Bahia está seriamente comprometida pela mancha fisiológica, cuja incidência é mais severa na época seca e fria do ano (maio a setembro).

Apesar de existirem cultivares que apresentam características que as tornam aceitas no mercado consumidor, é importante que sejam estudadas novas cultivares para ampliar as opções das poucas cultivares aceitas no exigente mercado internacional. A variedade Sekati, conhecida também como "Hong Kong Papaya", é o principal mamão do grupo 'Formosa' cultivado na Malásia, tendo grande aceitação no mercado asiático, e vem apresentando valores quase inexistentes de mancha fisiológica nos frutos, nas condições asiáticas. Além disso, pode representar uma boa alternativa para os produtores de mamão diminuirem o custo de produção, já que, por se tratar de uma variedade, as sementes desta possuem preços mais baixos que as sementes de híbridos, como o Tainung 01, atualmente o mais comercializado do grupo 'Formosa' no Brasil.

Baseando-se nisso, o trabalho teve como objetivo avaliar o comportamento da variedade Sekati do grupo 'Formosa' nas condições do oeste da Bahia, comparando com o híbrido Tainung 01 em relação às principais características fenotípicas das plantas, físicas e químicas dos frutos e à incidência de mancha fisiológica nos frutos, em diferentes épocas do ano.

\section{MATERIALEMÉTODOS}

O trabalho foi realizado em duas épocas do ano (primavera e verão), sendo avaliadas as características fenotípicas das plantas e físicas e químicas dos frutos da variedade Sekati e do híbrido Tainung 01 produzidos na Fazenda Agronol, localizada no município de Luiz

\footnotetext{
(Trabalho 103/2005). Recebido: 23/06/2005. Aceito para publicação: 17/02/2006.

${ }^{2}$ Eng. Agr. PhD, Prof. Adjunto IV da Faculdade de Agronomia e Medicina Veterinária (FAV) da Universidade de Brasília (UNB). Campos Universitáio Darcy Ribeiro, Cx.P. 04508, CEP 70910-970, Brasília-DF. kiyoshi@unb.br.

${ }^{3}$ Graduadps do curso de Agronomia da Faculdade de Agronomia e Medicina Veterinária (FAV) da Universidade de Brasília (UNB). Bolsistas IC / CNPq. rodrigommello@hotmail.com e vladmart@terra.com.br.

${ }^{4}$ Eng. Agr. MSc., Setor de Fruticultura da UnB. genifagundes@pop.com.br.
} 
Eduardo Magalhães, na região oeste da Bahia, com altitude de aproximadamente $800 \mathrm{~m}$. Segundo dados obtidos junto à estação meteorológica da propriedade, a temperatura média anual foi de $22^{\circ} \mathrm{C}$, com médias das temperaturas mínimas de $18^{\circ} \mathrm{C}$ e das máximas de $31^{\circ} \mathrm{C}$. A umidade relativa na época seca foi predominantemente baixa, com mínimas inferiores a 30\%. A precipitação pluviométrica média foi de $1.560 \mathrm{~mm} / \mathrm{ano}$.

Para a caracterização das plantas no campo, selecionaram-se, em agosto/2003, 20 plantas de cada cultivar, plantadas em jul/2002, em uma área de $60 \mathrm{ha}$, sob um mesmo pivô central. Os dados foram coletados na primavera (set/2003), época de maior incidência de mancha fisiológica nos frutos, e verão (jan/2004), época de menor incidência. Foram analisados os seguintes parâmetros: altura da planta, diâmetro do caule, número de folhas e frutos, comprimento da nervura central de folhas expandidas, teor de clorofila nas folhas e incidência de mancha fisiológica nos frutos.

O teor de clorofila foi determinado através de leitura direta em dez folhas por planta, com o colorímetro Minolta Corp modelo SPAD502. Os sintomas de mancha fisiológica nos frutos foram determinados visualmente, atribuindo-se notas: $0=$ nenhum sintoma; $1=1-30 \%$ da área total do fruto com sintomas; $2=31-70 \%$ da área total do fruto com sintomas, e $3=70-100 \%$ da área total do fruto com sintomas.

Coletaram-se em cada época 60 frutos/cultivar em estádio II (até $25 \%$ da superfície amarela), segundo escala de cores de mamão da FrutiSéries 7 (Brasil, 2000) para avaliação das características físicas e químicas, e avaliação da vida de prateleira em laboratório. Os frutos colhidos foram embalados em papel, colocados em caixas de papelão e transportados em carga seca até o laboratório de Fruticultura da Estação Experimental da Biologia da UnB. Após a chegada, os frutos foram lavados e distribuídos nos tratamentos: T1- frutos armazenados sob temperatura ambiente e analisados em ponto de consumo, T2 e T3armazenamento sob temperatura ambiente e em câmara fria $\left(\right.$ temp. $13^{\circ} \mathrm{C} \mathrm{e}$ $\mathrm{UR}=85-90 \%$ ), respectivamente, para estudo da vida de prateleira.

Nos frutos do T1, determinaram-se: peso, diâmetro, comprimento e formato do fruto, firmeza e espessura da polpa, cor da casca, formato da cavidade ovariana, sólidos solúveis (SS), acidez titulável (AT), pH e a relação SS/AT.

$\mathrm{O}$ formato do fruto foi determinado baseando-se nas seguintes formas: arredondada, oblongo-obovada, oblonga, obovada, alongada, piriforme-alongada, oblongo-alargada, alongado-arredondada e piriforme, conforme Figura 12.1 (Simão, 1998), e o formato da cavidade ovariana mediante comparação com a Figura 17 (Dantas et al., 2000), cujas formas podem ser: irregular, arredondada, angular, formato aproximado de estrela e estrela. A firmeza da polpa foi determinada realizando-se três inserções no fruto nas regiões basal, mediana e peduncular, com penetrômetro manual Fruit Pressure tester, modelo FT 327 , com ponteira de $7 \mathrm{~mm}$, sendo expressa em $\mathrm{kg} / \mathrm{cm}^{2}$. A espessura da polpa foi determinada com paquímetro digital Mitutoyo e expressa em milímetros.

Para determinação de SS, AT e pH, retiraram-se amostras de polpa de diferentes partes do fruto, fazendo-se uma homogeneização para obter a amostra, segundo metodologia proposta por Instituto Adolfo Lutz (1976). O teor de sólidos solúveis (SS) foi determinado por leitura direta em refratômetro manual, sendo os resultados expressos em ${ }^{\circ}$ Brix.
A AT (expressa em \% de ácido cítrico) foi obtida por titulação com $\mathrm{NaOH}(0,01 \mathrm{~N}) . \mathrm{O} \mathrm{pH}$ foi determinado pela leitura direta de uma amostra de polpa em pHmetro.

A vida útil pós-colheita dos frutos mantidos sem refrigeração (T2) e com refrigeração (T3) foi definida através de três variáveis: a perda de massa, a mudança na coloração da casca e o tempo de vida útil que o fruto apresentou a contar do dia da colheita até não estar mais em condições de ser comercializado e/ou consumido (início da senescência). A cor da casca foi determinada mediante comparação com a escala de cores da FrutiSéries 7 (Brasil, 2000), cujos estádios de maturação variam de 0 a 5, sendo: 0 (100\% verde); 1 (até 155 da superfície amarela); 2 (até $25 \%$ da superfície amarela); 3 (até 50\% da superfície amarela); 4 (50\% a $75 \%$ da superfície amarela), e 5 ( 76 a 100\% da superfície amarela).

As médias dos dados relativos à caracterização das plantas e às características físicas e químicas foram comparadas pelo teste Tukey, ao nível de 5\% de significância, sendo os dados sobre o estudo de vida de prateleira representados em figuras.

\section{RESULTADOS E DISCUSSÃO}

Nas plantas analisadas na primavera, houve diferença significativa entre a variedade Sekati e o híbrido Tainung 01 para as características: altura de planta, diâmetro do caule, $\mathrm{n}^{\circ}$ de frutos, teor de clorofila e incidência de mancha fisiológica nos frutos (Tabela 1). No verão, ocorreu o mesmo, exceto para os valores médios de comprimento da nervura central e teor de clorofila que não variaram entre as cultivares. Apesar de as plantas de Tainung 01 terem maiores valores para estas variáveis, observou-se que ambas as cultivares estudadas apresentaram um crescimento semelhante no período analisado (set. /2003 a jan. / 2004).

O fato de as plantas da variedade Sekati terem apresentado menor altura é uma boa característica, pois plantas altas, normalmente, apresentam entrenós de grande comprimento, sendo que os frutos ficam muito distanciados uns dos outros, causando maiores dificuldades para a sua colheita. Nos trabalhos de melhoramento, procura-se diminuir a altura da planta, selecionando-se as linhagens de menor porte, mas mantendo-se seu vigor (Mendes et al., 1996).

As plantas de 'Tainung 01' e de 'Sekati' apresentaram um pequeno desenvolvimento, e somente algumas características analisadas variaram entre as épocas. O fato de as plantas já estarem com um ano e dois meses de idade na primeira avaliação (primavera) pode justificar o baixo desenvolvimento destas na segunda avaliação (verão), pois a planta de mamoeiro, depois que inicia a produção, tende a se desenvolver mais lentamente.

O número de frutos das duas cultivares foi inferior no verão, sendo observada queda de 49\% (Tainung 01) e 34\% (Sekati) em relação à primavera. Ambas as cultivares produziram baixa quantidade média de frutos, variando de 4,5 a 20,8 frutos/planta. Marin et al. (1995) comentam que uma planta com boa capacidade produtiva é aquela que, após nove meses de plantio, produz número de frutos igual ou superior a 70. Dentre os fatores que podem ter influenciado a baixa produção de frutos, está o ataque de ácaro branco nas plantas e a colheita de frutos antes da avaliação, pois o experimento foi conduzido em uma área distante, não sendo possível evitar o acesso de pessoas no local.

TABELA 1 - Valores médios das características fenotípicas analisadas nas plantas do híbrido Tainung 01 e da variedade Sekati na primavera e no verão, nas condições do oeste da Bahia.

\begin{tabular}{|c|c|c|c|c|}
\hline \multirow[b]{2}{*}{ Parâmetro } & \multicolumn{2}{|c|}{ Primavera / 2003} & \multicolumn{2}{|c|}{ Verão / 2004} \\
\hline & Tainung 01 & Sekati & Tainung 01 & Sekati \\
\hline Altura (m) & $2,27 \mathrm{~b}$ & $1,36 \mathrm{~d}$ & $2,53 \mathrm{a}$ & $1,56 \mathrm{c}$ \\
\hline Diâmetro (cm) & $10,7 \mathrm{a}$ & $8,9 \mathrm{~b}$ & $11,0 \mathrm{a}$ & $9,4 \mathrm{~b}$ \\
\hline $\mathrm{N}^{\mathrm{o}}$ de frutos & $20,8 \mathrm{a}$ & $13,4 \mathrm{~b}$ & $10,1 \mathrm{c}$ & $4,5 \mathrm{~d}$ \\
\hline $\mathrm{N}^{\mathrm{o}}$ de folhas & $23,6 \mathrm{a}$ & $21,1 \mathrm{a}$ & $22,2 \mathrm{a}$ & $17,4 \mathrm{~b}$ \\
\hline Comprimento da nervura central $(\mathrm{cm})$ & $33,3 \mathrm{ab}$ & $32,4 \mathrm{~b}$ & $35,5 \mathrm{a}$ & $34,0 \mathrm{ab}$ \\
\hline Teor de Clorofila & $50,5 \mathrm{a}$ & $47,4 \mathrm{~b}$ & $42,6 \mathrm{c}$ & $45,7 \mathrm{bc}$ \\
\hline Incidência de Mancha Fisiológica & $0,6 \mathrm{a}$ & $0,0 \mathrm{~b}$ & $0,50 \mathrm{a}$ & $0,0 \mathrm{~b}$ \\
\hline
\end{tabular}

Rev. Bras. Frutic., Jaboticabal - SP, v. 28, n. 1, p. 79-82, Abril 2006 
TABELA 2 - Valores médios das características físicas e químicas de frutos de Tainung 01 e Sekati produzidos no oeste da Bahia.

\begin{tabular}{|c|c|c|c|c|}
\hline \multirow[b]{2}{*}{ Parâmetro } & \multicolumn{2}{|c|}{ Primavera / 2003} & \multicolumn{2}{|c|}{ Verão / 2004} \\
\hline & Tainung 01 & Sekati & Tainung 01 & Sekati \\
\hline Peso (g) & $979 \mathrm{c}$ & $1525 \mathrm{a}$ & $1128 b c$ & $1407 \mathrm{ab}$ \\
\hline Comprimento $(\mathrm{cm})$ & 22,9 a & $23,5 \mathrm{a}$ & $24,8 \mathrm{a}$ & $22,9 \mathrm{a}$ \\
\hline Diâmetro $(\mathrm{cm})$ & $9,9 \mathrm{a}$ & $10,5 \mathrm{a}$ & $9,5 \mathrm{a}$ & $10,6 \mathrm{a}$ \\
\hline Firmeza da polpa $\left(\mathrm{kg} / \mathrm{cm}^{2}\right)$ & $1,9 \mathrm{~b}$ & $3,1 \mathrm{a}$ & $1,3 \mathrm{~b}$ & $1,8 \mathrm{~b}$ \\
\hline Espessura da polpa (mm) & $23,9 \mathrm{~b}$ & $31,8 \mathrm{a}$ & $25,0 \mathrm{~b}$ & $30,5 \mathrm{a}$ \\
\hline $\mathrm{pH}$ & $5,1 \mathrm{~b}$ & $5,6 \mathrm{a}$ & $5,0 \mathrm{~b}$ & $5,2 \mathrm{~b}$ \\
\hline $\mathrm{SS}\left({ }^{\circ}\right.$ Brix $)$ & $10,9 \mathrm{ab}$ & $10,2 \mathrm{~b}$ & $11,8 \mathrm{a}$ & $11,3 \mathrm{ab}$ \\
\hline AT (\% ác. cítrico) & $0,044 \mathrm{~b}$ & $0,124 \mathrm{a}$ & $0,097 \mathrm{ab}$ & $0,079 \mathrm{ab}$ \\
\hline SS/AT) & $358 \mathrm{a}$ & $113 \mathrm{~b}$ & $154 \mathrm{~b}$ & $150 \mathrm{~b}$ \\
\hline
\end{tabular}

Valores seguidos de mesma letra, em cada linha, não diferem entre si, pelo teste de Tukey, ao nível de 5\% de significância.

Tanto na primavera, época de maior ocorrência da mancha fisiológica dos frutos, como no verão, a incidência de mancha fisiológica foi baixa nos frutos de 'Tainung 01' e nenhuma nos frutos de 'Sekati'. Como ainda não se sabe ao certo a causa da mancha fisiológica do mamão, sugere-se que alguns fatores possam ter contribuído para a menor incidência, como: tolerância do fruto à mancha, condições climáticas desfavoráveis à ocorrência da mancha, bom manejo da cultura (irrigação, adubação) e bom enfolhamento das plantas, permitindo melhor proteção dos frutos aos raios solares. Segundo observações de Ueno et al. (2002), plantas de mamoeiro mais vigorosas (maior enfolhamento, tronco com maior diâmetro) dentro de uma mesma área apresentaram menor intensidade de mancha fisiológica. Na cultura irrigada por pivô, o déficit hídrico, devido a problemas de dimensionamento e falta de um controle adequado de vazão das saídas de água, também pode influenciar na incidência de mancha fisiológica.

Os frutos de 'Sekati' analisados na primavera apresentaram maiores médias de peso $(1.525 \mathrm{~g})$, firmeza da polpa $\left(3,10 \mathrm{~kg} / \mathrm{cm}^{2}\right)$, espessura de polpa $(31,8 \mathrm{~mm}), \mathrm{pH}(5,65)$ e acidez titulável $(0,124 \%$ ácido cítrico), sendo que as demais características não diferiram estatisticamente daquelas do híbrido Tainung 01 (Tabela 2). Não houve diferença significativa entre os frutos das duas cultivares colhidos no verão, exceto para a característica espessura de polpa $(30,5 \mathrm{~mm})$, que foi maior na variedade Sekati.

Os frutos de Sekati apresentaram peso médio acima do intervalo considerado ideal para comercialização de frutos do grupo 'Formosa', que varia de 800 a $1.100 \mathrm{~g}$, de acordo com Costa e Pacova (2003). Já as demais características estão com valores dentro do ideal para frutos do grupo 'Formosa' destinados ao mercado interno. A firmeza de polpa, os teores de $\mathrm{SS}$, AT e o $\mathrm{pH}$, por exemplo, tiveram valores médios próximos aos obtidos por Fioravanço et al. (1994) e Leão (2001), que analisaram frutos deste grupo. A polpa dos frutos das duas cultivares, além do sabor agradável, apresentou espessura média acima de $20 \mathrm{~mm}$, que é considerado valor ideal para comercialização. Portanto, a variedade Sekati apresentou algumas características físicas (como firmeza e espessura de polpa) e químicas (como SS e pH) semelhantes e até superiores àquelas obtidas nos frutos de Tainung 01 , que já é bastante comercializado nos mercados interno e externo.

Os frutos de 'Sekati' colhidos na primavera amadureceram mais lentamente em relação aos frutos de 'Tainung 01', apesar de ambos serem colhidos no mesmo estádio de maturação e mantidos sob as mesmas condições de armazenamento (Figuras 1 e 2). Já nos frutos de 'Sekati' colhidos no verão ocorreu o oposto (Figuras 3 e 4). Como a vida útil pós-colheita dos frutos de 'Sekati' não diferiu daquela dos frutos de 'Tainung', o que pode explicar a diferença no amadurecimento são fatores fisiológicos dos frutos (teor de clorofila na casca, quantidade de etileno liberada pelo fruto, taxa respiratória e outros) e também o fato de a determinação do estádio de maturação para colheita ser baseado em análise visual da cor da casca. Yamanishi et al. (2004), acompanhando a evolução da coloração da casca de três cultivares de mamão com colorímetro, observaram uma variação na coloração das cultivares colhidas no mesmo estádio.

A vida útil pós-colheita dos frutos das duas cultivares colhidos na primavera e mantidas sob temperatura ambiente foi menor que a dos frutos colhidos no verão; já nos frutos mantidos sob refrigeração, a vida útil foi maior na primavera. Tanto nos frutos colhidos na primavera (Figuras 5 e 6) como no verão (Figuras 7 e 8), a perda de massa foi maior
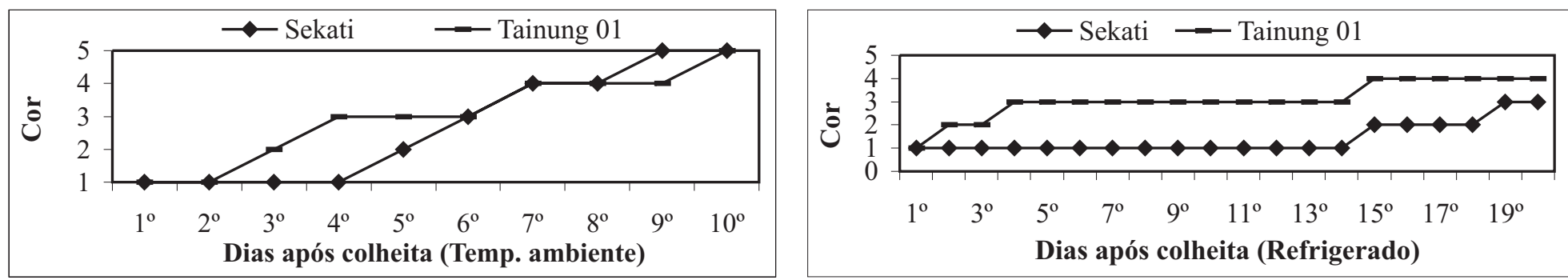

FIGURAS 1 e 2 - Evolução na cor da casca dos frutos de 'Sekati' e 'Tainung 01' colhidos na primavera e mantidos sob temperatura ambiente e sob refrigeração, respectivamente.
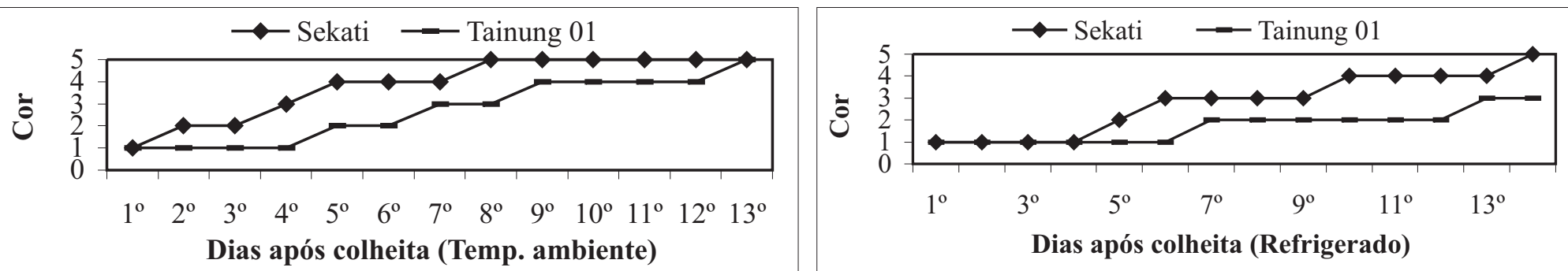

FIGURAS 3 e 4 - Evolução na cor da casca dos frutos de 'Sekati' e 'Tainung 01' colhidos no verão e mantidos sob temperatura ambiente e sob refrigeração, respectivamente. 

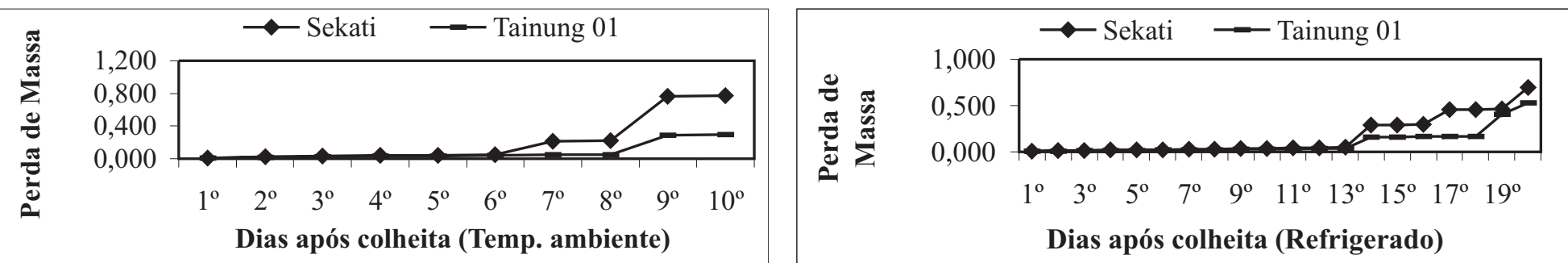

FIGURAS 5 e 6 - Perda de massa acumulada dos frutos de 'Sekati' e 'Tainung 01' colhidos na primavera e mantidos sob temperatura ambiente e sob refrigeração, respectivamente.
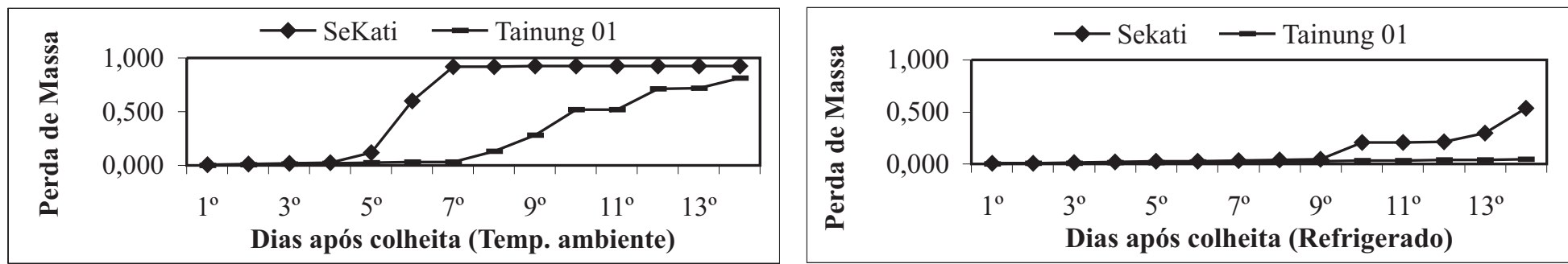

FIGURAS 7 e 8 - Perda de massa acumulada dos frutos de 'Sekati' e 'Tainung 01' colhidos no verão e mantidos sob temperatura ambiente e sob refrigeração, respectivamente.

na cultivar Sekati, independentemente das condições de armazenamento dos frutos. Mesmo tendo maior perda de massa, os frutos de Sekati tiveram tempo de prateleira semelhante aos de Tainung 01. Estando os frutos de ambas as cultivares nas mesmas condições de armazenamento, pode-se dizer que fatores como maior peso médio dos frutos, maior taxa de transpiração e presença de algum tipo de dano causado por inseto ou patógeno influenciaram na perda de massa dos frutos de Sekati.

\section{CONCLUSÕES}

1. Apesar de a variedade Sekati ter apresentado menor quantidade de frutos em relação ao Tainung 01 , destacou-se por apresentar menor altura de planta e maior tolerância à Mancha Fisiológica dos frutos.

2. Os frutos da variedade Sekati apresentaram, nas épocas estudadas, valores médios próximos aos do híbrido Tainung 01 para a maioria das características físico-químicas analisadas, o que pode ser um bom indicativo para a aceitação da variedade pelo mercado brasileiro.

\section{REFERÊNCIAS}

AGRIANUAL 2003: anuário estatístico da agricultura brasileira. São Paulo: FNP, Consultoria e Comércio, 2003.

BRASIL. Ministério da integração nacional. Mamão. Brasília, 2000. 8p. (FrutiSéries, 7).

COSTA, A. de F. S. da; PACOVA, B. E. V. Caracterização de cultivares, estratégias e perspectivas do melhoramento genético do mamoeiro. In: MARTINS, D. dos S.; COSTA, A. de F. S. da. A cultura do mamão: tecnologia e produção. Vitória-ES: INCAPER, 2003. cap. 3, p. $59-102$

DANTAS, J. L. L.; MORALES, C. F. G. Melhoramento genético do mamoeiro. In: MENDES, L. G.; DANTAS, J. L. L.; MORALES, C. F. G. Mamão no Brasil. Cruz das Almas-BA: EUFBA/EMBRAPACNPMF, 1996. p.93-120.

FIORAVANÇO, J. C.; PAIVA, M. C.; CARVALHO, R. I. N. de; MANICA, I. Características do mamão Formosa comercializado em Porto Alegre de outubro/91 a junho/92. Ciência Rural, Santa Maria-RS, v.24, n.3, p.519-522, 1994.
INSTITUTO ADOLFO LUTZ. Normas analíticas do Instituto Adolfo Lutz. São Paulo, 1976. v.1,371p.

LEÃO, R. Z. R. Qualidade dos frutos de mamoeiro (Carica papaya L.), cultivares Sunrise Solo e Tainung 1, produzidos nas regiões oeste e sul da Bahia. 2001. 99f. Dissertação (Mestrado em Agronomia) Faculdade de Agronomia e Medicina Veterinária, Universidade de Brasília, Brasília, 2001.

LIMA, H. C. Relações entre o estado nutricional, as variáveis do clima e a incidência da mancha fisiológica do mamão (Carica papaya $\mathrm{L}$.) no norte fluminense. 2003. Dissertação (Mestrado em Produção Vegetal), Centro de Ciência e Tecnologias Agropecuárias, Universidade Estadual do Norte Fluminense, Goytacazes-RJ, 2003.

MARIN, S. L. D.; GOMES, J. A.; SALGADO, J. S.; MARTINS, D. S.; FULLIN, E. A. Recomendações para a cultura do mamoeiro dos grupos Solo e Formosa no Estado do Espírito Santo. 4. ed. rev. ampl., Vitória: EMCAPA, 1995. 57p. (Circular Técnica, 3).

MENDES, L. G.; DANTAS, J. L. L.; MORALES, C. F. G. Mamão no Brasil. Cruz das Almas-BA: EUFBA/EMBRAPA-CNPMF, 1996. 179p.,

SIMÃO, S. Tratado de fruticultura. Piracicaba: FEALQ, 1998. 760p.

UENO, B.; CAMPOSTRINI, E.; NEVES, E. F.; FAGUNDES, G. R.; MACHADO FILHO, J. A.; YAMANISHI, O. K. Estudos sobre métodos de manejo da mancha fisiológica em frutos de mamoeiro (Carica papaya L.) no oeste da Bahia. Brasília: Setor de Fruticultura da Faculdade de Agronomia e Medicina Veterinária da Universidade de Brasília, 2002. 109p. (Documento,4).

VENTURA, J. A.; COSTA, H.; TATAGIBA, J. da S. Manejo das doenças do mamoeiro. In: MARTINS, D. dos S.; COSTA, A. de F. S. da. A cultura do mamão: tecnologia e produção. Vitória-ES: INCAPER, 2003. cap. 9, p. 231-308.

YAMANISHI, O. K.; FAGUNDES, G. R.; PIRES, M. de C.; MELLO, R. M. de; SACRAMENTO, E. R. S.; LIMA, L. A. de. Determinação da cor da casca de três cultivares de mamão com colorímetro Color Guide. In: CONGRESSO BRASILEIRO DE FRUTICULTURA, 18., 2004, Florianópolis-SC. Anais... Florianópolis:SBF, 2004. 